\title{
Firma Büyüklüğü Ve Borçlanmanın Kar Yönetimi Üzerindeki
} Etkisi

\author{
Mehmet AYGÜN * \\ Aysel AKÇAY_**
}

\section{ÖZET}

Bu çalışmanın temel amacı, kar yönetimi üzerinde firma büyüklüğü ve borçlanmanın etkisini incelemektir. 2009-2012 yıllarını kapsayan ve Borsa Istanbul'da kayıtl 230 firma verisinden yararlanılan çalışmada regresyon analizi yöntemi kullanılmıştır. Çalışmada firma büyüklüğü göstergesi olarak toplam varlıklar ve borçlanma göstergesi olarak da borçlanma oranı kullanılmıştır. Kar yönetiminin ölçümünde ise isteğe bağlı tahakkuklar kullanılmıştır. Çalışma sonucunda kar yönetimi ile firma büyüklüğü arasında pozitif bir ilişki bulunmuştur. Buna karşın kar yönetimi ile borçlanma oranı arasında negatif ve istatistiksel olarak anlamlı bir ilişkinin varlığı belirlenmiştir.

Anahtar Kelimeler: Kar Yönetimi, Firma Büyüklüğ̈̈, Jones Modeli, Borsa İstanbul. JEL Sınıflandırması: M41, M42, G30.

\section{Impact of Firm Size Indebtedness on Earnings Management}

\section{ABSTRACT}

The main purpose of this study is to investigate the effects of firm size and indebtedness on earning management. In the study including 2009-2012 periods and data's of 230 of Listing Istanbul, regression analysis is used. In the study total assets are used as proxy for firm size and indebtedness ratio is used as proxy for indebtedness. Discretionary accruals are used to measure the earning management. According to the results of the study, there is a positive relationship between the earning management and the firm size. However, there is a negative and statistically significant relationship between the earning management and the indebtedness.

Keywords: Earning Management, Firm Size, Jones Model, Listing Istanbul. Jel Classification: M41, M42, G30.

\footnotetext{
* Doç.Dr. Mehmet Aygün, Yüzüncü Yıl Üniversitesi, İktisadi ve İdari Bilimler Fakültesi, maygun@yyu.edu.tr

** Arş.Gör. Aysel Akçay, Yüzüncü Yıl Üniversitesi, İktisadi ve İdari Bilimler Fakültesi
} 


\section{GİRIŞ}

Genel kabul görmüş muhasebe ilkeleri, yöneticilere finansal tabloları düzenlemede bazı takdir yetkileri tanımıştır. Yöneticiler muhasebe seçimlerini maliyet paylaşımı, transfer fiyatlaması veya sermaye bütçelemesi gibi birbirleriyle ilişkili karar alma süreçlerini optimize etme amacıyla kullanabilmektedirler. Bununla birlikte yöneticilerin bazı takdirleri kötü yönde kullanmaları da söz konusu olabilmektedir. Yöneticilerin belirli muhasebe politikalarını iyimser veya etkili bir biçimde kullanıp kullanmadıkları muhasebe araştırmalarında uzun zamandan beri tartışılan bir konu olmaya devam etmektedir (Tang ve Chang, 2014).

2000'li yılların başında özellikle Amerika Birleşik Devletleri'nde yaşanan muhasebe skandalları dikkatlerin muhasebe manipülasyonlarına odaklanması ile sonuçlanmıştır. $\mathrm{Bu}$ manipülasyonlardan biri olarak, özellikle kar yönetimi konusunda kapsamlı bir literatür oluşmaktadır (Karacaer ve Özek, 2011)

Kar yönetimine genellikle literatürde iki farklı açıdan bakılmaktadır. İlk bakış açısında kar yönetimi, ortakların servetlerini maksimize etmek doğrultusunda yöneticilerin sorumluluklarını yerine getirmek amacıyla yararlandıkları bir yönetim aracı olarak düşünülmektedir (Bilgisel Bakış). İkinci bakış açısında ise kar yönetimine, finansal tablo kullanıcılarını yanlış yönlendirmek amacıyla ekonomik olayların çarpıtılması şeklinde bakılmaktadır (Fırsatçı Bakış). Kar yönetimi hakkındaki bu farklı görüşler, onun tanımlanmasında da farklılaşmalara sebep olmaktadır. (Ayarlıŏ̆lu, 2008). Aşağıda bu tanımlamalardan bazılarına yer verilmiştir:

Kar yönetimi ile ilgili ilk tanımlamalardan biri Schipper (1989) tarafindan yapılmıştır. Schipper (1989) kar yönetimini; bazı özel kazançlar elde etme niyetiyle, dışsal finansal raporlama sürecine kasıtlı bir müdahale şeklinde ifade etmiştir.

Healy ve Wahlen (1999) kar yönetimini, yöneticilerin firmanın ekonomik performans1 hakkında bazı paydaşları yanıltmak ya da kamuya açıklanan kâr rakamına bağlı bazı sözleşmelerden doğan sonuçları etkilemek amacıyla, finansal raporları oluşturma sürecinde ve gerçekleştirdikleri işlemlerde sahip oldukları yetkiyi kullanarak finansal raporları değiştirmeleri şeklinde tanımlamışlardır.

Mulford ve Comisky (2002) kar yönetimini; firma yönetimi tarafından belirlenmiş, piyasa analistleri tarafından öngörülmüş kâr rakamına ulaşabilmek ya da daha istikrarlı ve sürdürülebilir bir kâr trendi sağlamak amacıyla, kârların önceden belirlenmiş bir hedefe doğru etkin olarak manipüle edilmesi şeklinde tanımlamışlardır.

Küçüksözen (2005) bütün bu tanımlamalardan hareketle kar yönetimini şöyle tanımlamıştır: "bir şirketin ekonomik performansı hakkında finansal bilgi kullanıcılarının yanıltılması ya da kamuya açıklanan kar rakamına bağlı sözleşmesel sonuçların etkilenmesi amacıyla, yöneticilerin finansal raporlama sürecinde aldıkları kararlarla veya gerçekleştirdikleri işlemlerle finansal sonuçları değiştirmesidir. 
Kar yönetimi kavramı üzerine tartışmalar 1980'li yılların başlarına kadar uzanmaktadır. Konuya ilişkin ilk yapılan çalışmalarda bu kavramın ne olduğu (Healy,1985; DeAngelo vd, 1994; Burgstahler ve Dichev, 1997) nasıl tespit edileceği (Healy, 1985; DeAngelo, 1986; Jones,1991; Benish, 1999; Barton ve Simko, 2002) ve yöneticileri bu uygulamalara motive eden faktörlerin neler olduğu (Healy ve Wahen, 1999) araştırılmıştır. Kar yönetimi kavramı üzerinde bir uzlaşma sağlanamamasına karşın yapılan çalışmalarda kar yönetimini motive eden faktörler olarak ödül sözleşmeleri, yönetsel pozisyonlar, piyasa beklentileri, hisse senedi fiyatlarını dengelemek, vergiden kaçınma, kazanç düzeltmeleri ve temettü ödemelerinden kaçınma olarak belirlenmiştir (Naz vd, 2011).

Son yıllarda yapılan çalışmalarda ise kar yönetimi ile firma yapısına ilişkin faktörler (büyüklük, karlılık, borçlanma yeteneği, sermaye sahiplik yapısı), denetim kalitesi ve kurumsal yönetim arasındaki ilişkiler araştırılmaktadır.

$\mathrm{Bu}$ çalışmanın temel amacı, firmaya özgü faktörlerin (büyüklük ve borçlanma) kar yönetimi üzerindeki etkisini incelemektir. 2009-2012 yıllarını kapsayan çalışma Borsa İstanbul'a kayıtlı farklı sektörlerdeki firmalar üzerine yapılmıştır. Çalışmada firma büyüklük göstergesi olarak toplam varlıklar ve borçlanma göstergesi olarak da borçlanma oranı kullanılmıştır. Kar yönetimi göstergesi olarak ise literatür ile tutarlı bir biçimde isteğe bağlı tahakkuklar kullanılmıştır. İsteğe bağlı tahakkukların hesaplanmasında sonraki kısımlarda detaylı bir biçimde açıklanmış olan "Modifiye Edilmiş Jones Modeli" kullanılmıştır. Yapılan ampirik analiz sonucunda kar yönetimi firma büyüklügü arasında pozitif ancak istatistiksel olarak anlamlı olmayan bir ilişki olduğu görülmüştür. Buna karşın borçlanma oranı ile kar yönetimi arasında negatif ve istatistiksel olarak anlamlı sonuç elde edilmiştir.

Çalışma dört bölümden oluşmaktadır. Girişi takiben ikinci bölümde firma yapısı göstergeleri olarak kullanılan büyüklük ve borçlanma oranı ile kar yönetimi arasında literatürdeki çalışmalar özetlenmiştir. Üçüncü bölümde araştırma tasarımı hakkında bilgi verilmiştir. Son bölümde ise ampirik analiz sonuçları ve değerlendirme yer almaktadır.

\section{LITERATÜR TARAMASI}

\subsection{Kar Yönetimi ve Firma Büyüklüğü Arasındaki İlişki}

Firma büyüklüğü, kar yönetimini etkileyen önemli bir faktördür (Becker vd, 1998). Watts ve Zimmerman (1986) tarafından geliştirilen politik maliyetler hipotezine göre, özellikle büyük firmaların politik baskıları aşmak amacıyla gelecek dönemlere ilişkin kar açıklamaları erteleyecek muhasebe politikaları seçebileceklerini öne sürmüşlerdir. Başka bir ifade ile bu firma yöneticilerinin politik maliyetleri kısmak amacıyla karı azaltıcı uygulamalara yönelebilmeleri mümkündür. Bunun sonucu olarak bu firmalarda kar yönetimi uygulamalarının daha fazla olabileceği öne sürülmektedir (Wuryani, 2012). Öte yandan büyük firmaların, daha küçük olan firmalara göre dışarıdakiler (finansal veya yatırım analistleri) tarafından yakından gözlendiği bilinmektedir. Bu yüzden büyük firma yöneticilerinin 
raporlanmış kazançlar üzerinde davranışlarının daha kısıtlanacağı düşünülmektedir (Koh, 2003). Kar yönetimi üzerinde firma büyüklügünün etkisini inceleyen ampirik çalışmalar incelendiğinde karma sonuçların elde edildiği görülmektedir. Bu çalışmalardan bazıları aşağıda özetlenmiştir:

1990-1995 yıllarını kapsayan ve 803 gözlemden yararlandığı çalışmalarında Lobo ve Zhou (2001) firma büyüklüğü ile kar yönetimi arasında pozitif ve istatistiksel olarak anlamlı ilişkiler bulmuşlardır.

Barton ve Simko (2002) 200 firma verisinden yararlandıkları çalışmalarında büyük firmaların özellikle finansal tablo analistlerinin beklentileri doğrultusunda karlarını etkili bir biçimde yönettiklerine dair kanıtlara ulaşmışlardır.

Kim vd. (2003) kar yönetimi ile firma büyüklüğü arasındaki ilişkiyi incelediği çalışmaları sonucunda firma büyüklüğünün kar yönetimi üzerinde önemli bir etkisinin olduğunu tespit etmiş̧lerdir. Yapılan analiz sonucunda küçük firmalar ile karşılaştırıldığında orta ve büyük ölçekli firmaların kar yönetimi uygulamalarının varlığı tespit edilmiştir.

Bangladeş firmaları üzerine yaptıkları çalışmalarında Razzaque vd. (2006) firma büyüklüğünün kar yönetimi üzerinde pozitif bir etkisinin olduğunu tespit etmişlerdir.

Hong Kong borsasına kayıtlı aile firmaları üzerine yaptıkları çalışmalarında Jaggi vd (2009) firma büyüklüğü ile kar yönetimi arasında negatif ve istatistiksel olarak anlamlı bir ilişki bulmuşlardır.

2006-2010 yıllarını kapsayan ve Pakistan borsası üzerine yaptıkları çalışmalarında Naz vd. (2011) firma büyüklüğü ile kar yönetimi arasında anlamlı bir ilişki bulamamışlardır. Benzer sonuç Tahran borsası üzerine yaptıkları çalışmalarında Emamgholipour vd. (2013) tarafından da elde edilmiştir.

Tunus firmaları üzerine yaptıkları çalışmalarında Lanouar vd. (2013) firma büyüklüğünün kar yönetiminin önemli bir belirleyicisi olduğunu tespit etmiştir. Başka bir ifade ile kar yönetimi ile firma büyüklüğü arasında pozitif bir ilişkinin varlığı belirlenmiştir.

Tahran borsası üzerine yaptıkları ve 2008-2010 yılları verilerinden yararlandıkları çalışmalarında Rahmani ve Akbari (2013) kar yönetimi ile firma büyüklüğü arasında pozitif ve istatistiksel olarak anlamlı sonuçlar elde etmişlerdir.

Yukarıdaki teorik ve ampirik çalışmalar doğrultusunda aşağıdaki hipotez geliştirilmiştir.

H1: Kar yönetimi ile firma büyüklüğü arasında anlamlı bir ilişki vardır.

\subsection{Kar Yönetimi ve Borçlanma Arasındaki İlişki}

Watts ve Zimmerman (1986) borçlanma oranının yüksek olduğu firma yöneticilerinin kredi sağlayan kurumlar ile görüşmeleri süresinde karlarını yapay olarak arttırma eğiliminde olacaklarını ileri sürmüşlerdir. Bu durum literatürde Borç/Öz kaynaklar hipotezi olarak 
bilinmektedir. $\mathrm{Bu}$ hipoteze göre bir işletmenin borç/öz kaynaklar oranı ne kadar yüksek olursa, işletme yöneticilerinin raporlanan kazancı gelecek dönemlerden cari döneme kaydıran muhasebe politikalarını seçme olasılığının o kadar yüksek olacağını ifade etmektedir. Bu bağlamda kar yönetimi ile borçlanma oranı arasında anlamlı bir ilişkinin olduğu söylenebilir.

Konuya ilişkin yapılan ampirik çalışmalarda bu hipotezi destekleyen sonuçlar elde edildiği gibi tersi sonuçların olduğu da görülmektedir. Aşağıda literatürde yapılan bazı çalışmalar özetlenmiştir.

Belçika firmaları üzerine yaptıkları çalışmalarında Sercu vd. (2006) kar yönetimi ve borçlanma oranı arasındaki ilişkiyi araştırmışlardır. Yapılan analiz sonucunda kar yönetimi ile borçlanma oranı arasında pozitif bir ilişkinin olduğunu tespit etmişlerdir.

Çin sermaye piyasası üzerine yaptıkları çalışmalarında Zhaoguo ve Xiaoxia (2009) sermaye yapısı ve kar yönetimi arasındaki ilişkiyi incelemişlerdir. 2003-2007 yıllarını kapsayan çalışma sonucunda söz konusu değişkenler arasında pozitif bir ilişkinin varlığı belirlenmiştir.

İspanya Borsası üzerine yaptıkları 1992-2002 yıllarını kapsayan ve çeşitlendirmeye yapan firmalar üzerine yaptıkları çalışmalarında Rodriguez-Peres ve van Hemmen (2010) kar yönetimi ve borçlanma arasındaki ilişkiyi incelemişlerdir. Yapılan analiz sonucunda çeşitlendirme düzeyi düşük olan firmalarda kar yönetimi ile borçlanma arasında negatif bir ilişkinin olduğu tespit edilmiştir.

Brezilya borsası üzerine yaptıkları ve 2004-2010 yıllarını kapsayan çalışmaları sonucunda Ardison vd. (2012) borçlanma oranı ile kar yönetimi arasında anlamlı bir ilişki bulamamışlardır.

2003-2006 yıllarını kapsayan ve Malezya firmaları üzerine yaptıkları çalışmaları sonucunda Mohammad vd (2012) kar yönetimi ile borçlanma oranı arasında negatif ve istatistiksel olarak anlamlı sonuçlar elde etmişlerdir. Benzer sonuçlar Kore firmaları üzerine yaptıkları çalışmalarında Nam vd (2012) tarafından da elde edilmiştir.

Jensen (1986) göre borçlanma oranı yüksek olan firmalar, kredi sağlayan kurumlar tarafindan sürekli kontrol altındadırlar. Bu bağlamda bu firma yöneticilerinin kar yönetimi uygulamalarının kısıtlanacağı düşünülmekte ve aşağıdaki hipotez geliştirilmiştir.

H2: Kar yönetimi ile borçlanma arasında anlamlı bir ilişki vardır.

\section{ARAŞTIRMA TASARIMI}

Çalışmanın bu kısmında, örneklem, araştırma modeli ve değişkenlerin hesaplanmasına ilişkin prosedür açıklanmıştır.

\section{1. Örneklem}

Çalışmada Borsa İstanbul'a kayıtlı farklı sektörlerden 230 firma verisinden yararlanılmıştır. Varlık yapılarının farklı olması nedeniyle bankacılık, sigortacılık ve finans 
sektöründe yer alan firmalar kapsam dışı tutulmuştur. 2009-2012 yıllarını kapsayan çalışmada aşağıda tanımlamaları yapılan tüm değişkenlere ilişkin veriler Kamuyu Aydınlatma Platformu'nun resmi web sayfasından (www.kap.gov.tr) sağlanmıştır.

\subsection{Araştırma Modeli}

Kar yönetimi üzerinde firma büyüklüğü ve borçlanmanın etkisini inceleyen bu çalışmada geliştirilen hipotezleri test etmek amacıyla aşağıdaki modeller oluşturulmuştur:

MODEL 1: TAHAKKUK ${ }_{i t}=\beta o+\beta 1 B \ddot{U} Y \ddot{U K L} \ddot{U} K_{i t}+\varepsilon_{i t}$

MODEL 2: TAHAKKUK $K_{i t}=\beta o+\beta 1 B O R C ̧ L A N M A_{i t}+\varepsilon i t$

MODEL 3: TAHAKKUK $K_{i t}=\beta o+\beta 1 B \ddot{U} Y \ddot{U} K L \ddot{U} K_{i t}+\beta 2 B O R C ̧ L A N M A_{i t}+\varepsilon_{i t}$

Burada, TAHAKKUK ${ }_{i t}, \mathrm{t}$ döneminde i firmasının kar yönetimini; BÜYÜKLÜK $K_{i t}, \mathrm{t}$ döneminde i firmasının firma büyüklüğünü, $B O R C ̧ L A N M A_{i t} \mathrm{t}$ döneminde $\mathrm{i}$ firmasının borçlanma oranını ve sit ise hata terimini göstermektedir.

\subsection{Değişkenler}

\subsubsection{Bağımlı Değişken}

Çalışmada bağımlı değişken olarak kar yönetimi kullanılmıştır. Literatürde konuya ilişkin daha önceki yapılan çalışmalar ile tutarlı bir biçimde kar yönetiminin ölçümünde isteğe bağlı tahakkuklar kullanılmıştır. Daha önce de ifade edildiği gibi isteğe bağlı tahakkukların ölçümünde birçok model geliştirilmiştir. Dechow vd. (1995) isteğe bağlı tahakkuklarının ölçümünde en etkili modelin Modifiye Edilmiş Jones Modeli olduğunu ifade etmişlerdir. Konuya ilişkin ampirik çalışmalarda (Caneghem, 2002; Klein, 2002; Koh, 2003; Liu ve Lu, 2007) bu çalışmada olduğu gibi kar yönetimi göstergesi olarak kabul edilen isteğe bağl1 tahakkukların hesaplanmasında "Modifiye Edilmiş Jones Modeli"nin kullanıldığı görülmektedir. 1991 yılında Jones tarafından ortaya atılan daha sonra Dechow ve diğerleri (1995) tarafından geliştirilerek “Modifiye Edilmiş Jones Modeli”ne göre isteğe bağlı tahakkuklar şöyle hesaplanmaktadır:

$$
D A C C_{i t}=\operatorname{TACC}_{i t} / A_{i t-1}-\left[\hat{\alpha}_{t}\left(1 / A_{i t-1}\right)\right]+\hat{\alpha}_{1 i}\left[\left(\Delta R E V_{i t}-\Delta R E C_{i t}\right) / A_{i t-1}\right]+\hat{\alpha}_{2 i}\left[P P E_{i t} / A_{i t-1}\right]
$$

Burada,

$\mathrm{DACC}_{i t}, \mathrm{t}$ döneminde i firmasının isteğe bağlı tahakkuklarını, $\mathrm{TACC}_{i t}{ }^{1}, \mathrm{t}$ döneminde $\mathrm{i}$ firmasının toplam tahakkukları $\triangle \mathrm{REV}_{i t}, \mathrm{t}$ döneminde i firmasının satış gelirlerindeki değişimi, $\Delta \mathrm{REC}_{i t}$, $\mathrm{t}$ döneminde $\mathrm{i}$ firmasının ticari alacaklarındaki değişimi, $\mathrm{PPE}_{i t}$, $\mathrm{t}$ döneminde $\mathrm{i}$ firmasının maddi duran varlık alımını, $\mathrm{A}_{i t-1}$ ise t-1 döneminde i firmasının toplam varlıklarını göstermektedir.

\footnotetext{
${ }^{1}$ TACCit=NIit-OCFit şeklinde hesaplanmıştır. NIit, $t$ döneminde i firmasının net karını, OCFit, $t$ döneminde $\mathrm{i}$ firmasının faaliyetlerden sağlanan nakit akımlarını göstermektedir.
} 


\subsubsection{Bağımsız Değişkenler}

Çalışmada kullanılan bağımsız değişkenler olarak firma büyüklüğü ve borçlanma oranı kullanılmıştır. Firmaların ilgili yıllardaki mali tablolarından elde edilen bu değişkenler aşağıda gösterildiği gibi hesaplanmıştır:

BÜYÜKL $\ddot{U} K=$ Firma toplam varlıklarının doğal logaritması

BORÇLANMA $=\left(\right.$ Kısa Vadeli Borçlar ${ }_{i t}+$ Uzun Vadeli Borçlar $\left._{i t}\right) /$ Toplam Varlıklar $_{i t}$

\section{AMPİIIK ANALIZZ VE DEĞERLENDİRME}

Tablo 1'de yukarıda geliştirilen modellerde kullanılan değişkenlere ait özet istatistiki bilgiler yer almaktadır. İsteğe bağlı tahakkukların \% 0,91 ile $\% \quad-0,73$ arasında olduğu görülmektedir. Ortalama ve standart sapma ise sirasıly \% $-0,0071$ ve \% 0,13344 olarak hesaplanmıştır. Bu sonuç, örneklem hacmine dahil edilen firmaların ortalama olarak negatif isteğe bağlı tahakkuklara sahip olduğunu göstermektedir. Öte yandan bağımsız değişkenler olarak kullanılan büyüklük ve borçlanma oranları ortalaması ise sırasıyla 8,04 ve \% 45 ' dır.

Tablo 1. Özet İstatistik

\begin{tabular}{|c|c|c|c|c|c|}
\hline & GÖZLEM & MINIMUM & MAKSIMUM & ORTALAMA & STANDART SAPMA \\
\hline TAHAKKUK & 967 &,- 73 &, 91 &,- 0071 &, 13344 \\
\hline BÜYÜKLÜK & 967 & 5,71 & 10,27 & 8,0431 &, 82145 \\
\hline BORÇLANMA & 967 &, 01 &, 92 &, 4539 &, 23201 \\
\hline
\end{tabular}

Tablo 2'de hipotezleri test etmek üzere geliştirilen regresyon analizi sonuçları yer almaktadır. Hipotez değişkenlerinin modele etkisini test etmek için iki regresyon modeli kurularak analiz edilmiş; üçüncü modelde ise tüm değişkenler regresyon analizine dahil edilmiştir.

Model 1'de kar yönetimi göstergesi olarak kullanılan tahakkuklar ile büyüklük arasındaki regresyon analizi sonuçları görülmektedir. Tablo incelendiğinde tahakkuklar ile firma büyüklüğü arasında pozitif ancak istatistiksel olarak anlamlı olmayan bir ilişkinin var olduğu görülmektedir. Bu sonuç H1 hipotezimizi desteklememektedir.

Model 2'de kar yönetimi göstergesi olarak kullanılan tahakkuklar ile borçlanma arasındaki regresyon analizi sonuçları görülmektedir. Sonuçlar incelendiğinde H2 hipotezini destekler bir sonucun varlığına ulaşılmıştır. Tahakkuklar ile borçlanma arasında negatif ve istatistiksel olarak \% 1 düzeyinde anlamlı bir ilişki vardır. Diğer bir ifade ile borçlanma oranı yüksek olan firmalarda kar yönetimi uygulamalarının düşük olduğu sonucu elde edilmiştir. Bu sonuç, borçlanma oranın kar yönetimini engelleyen bir unsur olduğu şeklinde yorumlanabilir. Daha önce ifade edildiği gibi Jensen (1986) tarafından geliştirilen hipoteze göre, borçlanma 
oranı yüksek olan firmalar, kredi sağlayan kurumlar tarafından sürekli kontrol altındadırlar. Başka bir ifade ile bu firma yöneticilerinin karı yönetme noktasında bazı kısıtlayıcı unsurların varlığı söz konusudur. Elde edilen sonuç, bu ifadeyi desteklemektedir.

Model 3'te çoklu regresyon analizi sonuçları yer almaktadır. Model 1 ve Model 2 sonuçlarını teyit eder bir biçimde, kar yönetimi ile büyüklük arasında pozitif; borçlanma arasında ise negatif ve istatistiksel olarak da oldukça anlamlı sonuçlar elde edilmiştir.

Tablo 2. Regresyon Analizi Sonuçları

\begin{tabular}{|c|c|c|c|}
\hline \multirow{2}{*}{$\begin{array}{c}\text { DEĞİŞKENLER } \\
\text { VE PARAMETRELER }\end{array}$} & \multicolumn{3}{|c|}{ BAĞIMLI DEĞİŞKEN: TAHAKKUK } \\
\hline & MODEL 1 & MODEL 2 & MODEL 3 \\
\hline SABITT & $\begin{array}{c}-, 007 \\
(-, 171)\end{array}$ & $\begin{array}{c}, 029 \\
(3,088)^{* * *}\end{array}$ & $\begin{array}{c}, 020 \\
(, 474)\end{array}$ \\
\hline BÜYÜKLUK & $\begin{array}{l}, 000 \\
(, 003)\end{array}$ & & $\begin{array}{l}.007 \\
(, 212)\end{array}$ \\
\hline BORÇLANMA & & $\begin{array}{c}-, 138 \\
(-4,321)^{* * *}\end{array}$ & $\begin{array}{c}-, 138 \\
(-4,324) * * *\end{array}$ \\
\hline Düzeltilmiş $\mathbf{R}^{2}$ & ,002 & 018 & 017 \\
\hline Gözlem Sayısı & 967 & 967 & 967 \\
\hline
\end{tabular}

Parantez içerisindekiler $\mathrm{t}$ değerlerini göstermektedir.

Sırasıyla ***, \% 1; **, \% 5 ve *, \% 10 düzeyinde anlamlılığı ifade etmektedir.

\section{SONUÇ VE DEĞERLENDİRME}

Bu çalışmada Borsa İstanbul'a kayıtlı farklı sektörlerde faaliyette bulunan 230 firma verisine ait 967 gözlemden yararlanılarak kar yönetimi üzerinde firma büyüklügü ve borçlanma oranının etkisi araştırılmıştır. Çalışmada, kar yönetimi isteğe bağlı tahakkuklar ile ölçülmüş ve "Modifiye Edilmiş Jones Modeli" kullanılmıştır. Dechow vd. (1995) kar yönetimini ölçmede kullanılan en etkili modelin "Modifiye Edilmiş Jones Modeli" olduğunu ifade etmişlerdir. Çalışmada, firma büyüklük göstergesi olarak toplam varlıklar, borçlanma göstergesi olarak da borçlanma oranı kullanılmıştır. Ampirik analizlerde regresyon analizinden yararlanılmıştır. Yapılan analiz sonucunda kar yönetimi ile firma büyüklüğü arasında pozitif ancak istatistiksel olarak anlamlı olmayan bir sonucun olduğu görülmüştür. Buna karşın borçlanma oranı ile kar yönetimi arasında negatif ve istatistiksel olarak oldukça anlamlı sonuçlar elde edilmiştir.

Güncel veriler kullanılarak yapılan ve bu noktada son derece önemli olan çalışma bazı kısıtlamaları da içermektedir. Öncelikle çalışmada firma yapısı göstergeleri olarak sadece büyüklük ve borçlanma oranından yararlanılmıştır. Firma karlılığı, yatırım firsatları ve temettü ödemeleri gibi diğer faktörler dikkate alınmamıştır. Bunun yanı sıra daha önce ifade edildiği gibi konuya ilişkin son dönemlerde yapılan çalışmalarda denetim ve kurumsal yönetim boyutları incelenmemiştir. Konuya ilişkin daha sonra yapılacak çalışmalarda bu noktalar göz önünde bulundurulabilir. 


\section{KAYNAKLAR}

ARDISON, Kym Marcel Martins., Antonio Lopo,MARTINEZ and Fernando Caio,GALDI (2012), "The Effect Of Leverage On Earnings Management İn Brazil” Advances İn Scientific And Applied Accounting”, Vol.5, No.3, pp.305-324

AYARLIOĞLU, Mehmet Akif, (2008), "Kar Yönetimi Uygulamaları Ve İstanbul Menkul Kıymetler Borsasında Test Edilmesi”, Yayımlanmamış Doktora Tezi, Hacettepe Üniversitesi Sosyal Bilimler Enstitüsü

BARTON, Jan, and Paul J. SIMKO (2002), “The Balance Sheet As An Earnings Management Constraint”, The Accounting Review, Vol: 77, pp: 1-27.

BECKER, Connie L., Mark L. DEFOND, James JIAMBALVO, and K. R. SUBRAMANYAM. (1998), "The Effect Of Audit Quality On Earnings Management”, Contemporary Accounting Research, Vol: 15, No: 1, pp: 1-24.

BENEISH, Messod D., (1999), “The Detection Of Earnings Manipulation”, Financial Analysts Journal, Vol: 55, No: 5, September/October, pp: 24-36.

BURGSTAHLER, David, and Ilia DICHEV (1997), "Earnings Management To Avoid Earnings Decreases And Losses”, Journal of Accounting and Economics, 24, pp.99126.

CANEGHEM, T.Van, (2002), "Earnings Management İnduced By Cognitive Reference Points”, British Accounting Review, vol.34, pp.167-178.

DEANGELO, Linda Elizabeth, (1986), “Accounting Numbers As Market Valuation Substitutes: A Study Of Management Buyouts Of Public Stockholders”, The Accounting Review, Vol: LXI, No: 3, pp: 400-420.

DEANGELO, Harry, DEANGELO, Linda, and Douglas, SKINNER (1994), "Accounting Choice İn Troubled Companies", Journal of Accounting and Economics 17, pp.113143.

DECHOW, Patricia M., Richard G. SLOAN and Amy P. SWEENEY (1995), "Detecting Earnings Management”, The Accounting Review, 70(2), pp.193-225.

EMAMGHOLIPOUR, Milad, Seyedeh Maryam Bababnejad BAGHERİ, Elham MANSOURINİA, and Ali Mohammadpour ARABI (2013), “A Study On Relationship Between İnstitutional İnvestors And Earning Management: Evidence From The Tehran Stock Exchange”, Management Science Letters 3, pp1105-112.

JAGGI, Bikki, Sidney LEUNG ve Ferdinand GUL (2009) "Family Control, Board İndependence And Earnings Management: Evidence Based On Hong Kong Firms" Account. Public Policy 28, pp. 281-300

JENSEN, Michael, (1986), “Agency Costs Of Free Cash Flow, Corporate Finance And Takeovers”, American Economic Review, 76, pp.323-329 
JONES, Jennifer J., (1991), “Earnings Management During Import Relief Investigations”, Journal of Accounting Research 29, pp.193-228.

HEALY, Paul M., (1985), “The Effect Of Bonus Schemes On Accounting Decisions”. Journal Of Accounting And Economics”, 7 (1-3), pp.85-107.

HEALY. Paul, and James WAHLEN (1999) "A Review Of The Earnings Management Literature And İts İmplications For Standard Setting", Accounting Horizons, pp.365383.

KARACAER, Semra, ve Pelin ÖZEK (2011), "Denetim Firmasının Büyüklüğü Ve Kar Yönetimi İlişkisi: İMKB Şirketleri Üzerine Ampirik Bir Araştırma”, Muhasebe ve Finansman Dergisi, ss.60-74

KIM, Yangseon, Caixing LIU, and S. Ghon RHEE. (2003), “The Effect Of Firm Size On Earnings Management”,

http://www2.hawaii.edu/ fima/PDF/Finance_Seminar/EarningsMgmt.pdf

KLEIN, April, (2002), “Audit Committee, Board Of Director Characteristics, And Earnings Management”, Journal of Accounting and Economics, vol.33, no.3, pp.375-400.

KOH, Ping-Sheng, (2003), “On The Association Between İnstitutional Ownership And Aggressive Corporate Earnings Management İn Australia”, The British Accounting Review, vol.35, pp. 105-128.

KÜÇÜKSÖZEN, Cemal, (2005), Finansal Bilgi Manipülasyonu: Nedenleri, Yöntemleri, Amaçları, Teknikleri, Sonuçları Ve İMKB Şirketleri Üzerine Ampirik Bir Çalışma”, Sermaye Piyasası Kurulu, Yayın No: 183, Ankara.

LANOUAR, Charfeddine, Rabeb RİAHİ and Abdelwahed OMRI (2013), "The Determinants Of Earnings Management İn Developing Countries: A Study In The Tunisian Context”, The IUP Journal of Corporate Governance, Vol. XII, No. 1, pp. 35-49

LIU, Qiao and LU, Zhou (2007), "Corporate Governance And Earnings Management İn The Chinese Listed Companies: A Tunnelling Perspective”, Journal of Corporate Finance, vol.13, pp. 881-906.

LOBO, Gerald, and Jian ZHOU, (2001), "Disclosure Quality And Earnings Management", Asia-Pacific Journal of Accounting and Economics 8 (I), pp.1-20

MOHAMMED, Muslim Har Sani, Hafiz Majdi Abdul RASHID ve Fekri Ali Mohammed SHAWTARI, (2012) “Corporate Governance And Earnings Management İn Malaysian Government Linked Companies The İmpact Of Glcs' Transformation Policy”, Asian Review of Accounting, Vol. 20 No. 3, pp. 241-258

MULFORD, Charles W, and Eugene E. COMISKEY (2002), The Financial Numbers Game, Detecting Creative Accounting Practices, John Wiley \& Sons, Inc., United States of America. 
NAM, Hye-Jeong, Jong-Hag CHOI, Joseph COMPRIX ve Helen Hyejin KWON (2012) "Firm Location And Earnings Management: Korean Evidence”, Asia-Pacific Journal of Accounting \& Economics, Vol. 19, No. 3, pp. 292-317

NAZ, Iram, Khurram BHATTI, Abdul GHAFOOR, and Habib Hussain KHAN (2011), "Impact Of Firm Size And Capital Structure On Earnings Managment: Evidence From Pakistan”, International Journal of Contemporary Business Studies, Vol. 2, No: 12, pp.22-31.

RAHMANI, Samira and Mir Askari AKBARI (2013), "Impact Of Firm Size And Capital Structure On Earnings Management: Evidence From Iran”, World of Sciences Journal, Vol.1, Issue. 17, pp.59-71.

RAZZAQUE, Rezaur M, Muhammad Zahedur, RAHMAN, and Amirus SALAT (2006). “Earnings Management: An Analysis On Textile Sector Of Bangladesh”, The Cost and Management. 34(5), pp. 5-13.

RODRIQUEZ-PERES, Gonzalo and Stefan. Van HEMMEN (2010), "Debt Diversification And Earnings Management”, Journal of Accounting and Public Policy, 29 (2), pp.138159.

SERCU, Piet, Heidi VANDER BAUWHEDE, and Marleen WİLLEKENS (2006), "Earning Management And Debt”, https://lirias.kuleuven.be/bitstream/123456789/120984/1/afi_0619.pdf

SCHIPPER, K., (1989), “Commentary On Earnings Management”, Accounting Horizons, 3 (4), pp.91-102.

TANG, Hui-Wen, and Chong-Chuo CHANG (2014), "Does Corporate Governance Affect The Relationship Between Earnings Management And Firm Performance? An Endogenous Switching Regression Model”, Rev Quant Finan Acc

ZHAOGUO, Zhang, and Liu XIAOXIA (2009), "The Effects Of Capital Structure On Earnings Management: Empirical Evidence From China”, The 1st International Conference on Information Science and Engineering, pp. 4564-4568

WATTS, Ross L., and Jerold L. ZIMMERMAN. (1986), Positive Accounting Theory, First Edition, New Jersey, Prentice Hall, Inc.

WURYANI, Eni, (2012) “Company Size İn Response To Earnings Management And Company Performance”, Journal of Economics, Business and Accountancy Ventura, Vol.15, No.3, pp. 491-506 
